\title{
The effect of cardiac geometry variation according to sex and race on outcomes in patients with acute coronary syndrome undergoing percutaneous coronary intervention
}

Edward T. Ha ${ }^{1}$, Marc Cohen ${ }^{2,3}$, Theodore J. Gaeta ${ }^{4,5}$, Manish A. Parikh ${ }^{1,5}$, Stephen J. Peterson ${ }^{1,5}$, Wilbert S. Aronow 6,7

\author{
${ }^{1}$ Department of Internal Medicine, New York-Presbyterian Brooklyn Methodist \\ Hospital, Brooklyn, NY, USA \\ ${ }^{2}$ Department of Cardiology, Newark Beth Israel Medical Center, Newark, NJ, USA \\ ${ }^{3}$ Department of Medicine, Rutgers-New Jersey Medical School, Newark, NJ, USA \\ ${ }^{4}$ Department of Emergency Medicine, New York-Presbyterian Brooklyn Methodist \\ Hospital, Brooklyn, NY, USA \\ ${ }^{5}$ Department of Medicine, Weill Cornell Medical College, New York, NY, USA \\ ${ }^{6}$ Department of Cardiology, Westchester Medical Center, Valhalla, NY, USA \\ ${ }^{7}$ Department of Medicine, New York Medical College, Valhalla, NY, USA
}

Submitted: 23 February 2021

Accepted: 17 June 2021

Arch Med Sci Atheroscler Dis 2021; 6: e152-e159

DOI: https://doi.org/10.5114/amsad.2021.107908

Copyright (c) 2021 Termedia \& Banach

\begin{abstract}
Introduction: The prevalence and long-term consequences of differences in baseline cardiac geometry (as a result of hypertension) in patients undergoing percutaneous coronary intervention ( $\mathrm{PCl}$ ) for acute coronary syndrome (ACS) are ill-defined. The primary purpose of this study was to clarify whether there were differences among sexual and racial groups in echocardiographic findings reflecting cardiac geometry and adaptation in patients undergoing $\mathrm{PCI}$ for ACS and whether this could explain the differences in outcomes seen between these groups.

Material and methods: We analyzed 1-year follow-up data from a single institution, a retrospective, observational study that enrolled 1,153 patients who presented with ACS and were treated with $\mathrm{PCl}$, for whom echocardiographic data were available.

Results: Normal, concentric hypertrophy, and eccentric hypertrophy in males vs. females were observed as follows: $29 \%$ vs. $19 \%$ ( $p=0.001$ ), $25 \%$ vs. $31 \%$ $(p=0.02)$, and $8 \%$ vs. $14 \%(p=0.004)$, respectively. The primary endpoint of all-cause death $(n=89,7.7 \%)$ occurred in $48(10.5 \%)$ females and in 41 $(8.2 \%)$ males, $p=0.03$. Major adverse cardiac events and bleeding (MACE-B - all-cause death, non-fatal myocardial infarction, stroke or hospitalization for bleeding) was higher among women than men $(21.6 \%$ vs. $13.5 \%, p=$ $0.0002)$. Males with eccentric hypertrophy $(E H)$ had similar MACE-B outcomes as females with EH 1 -year post- $\mathrm{PCl}$ ( $29 \%$ vs. $32 \%$, respectively, $p=$ $0.77)$.

Conclusions: Females undergoing $\mathrm{PCI}$ for $\mathrm{ACS}$ are at higher risk for worse outcomes because they are more likely to express the eccentric hypertrophy phenotype; however, it did not account for the difference in adverse outcomes observed between sexes.
\end{abstract}

Key words: heart failure, heart attack, sex, left ventricular hypertrophy, major adverse cardiac events, race, differences, myocardial infarction.

\author{
Corresponding author: \\ Edward Ha, MD, MSc \\ New York-Presbyterian \\ Brooklyn Methodist \\ Hospital \\ $5066^{\text {th }}$ Street \\ Brooklyn, NY 11215, USA \\ 718-780-3000 \\ E-mail: edh9028@nyp.org
}




\section{Introduction}

Patients with acute coronary syndrome (ACS) represent a heterogeneous population. Sex and racial differences in patient presentation may affect treatment decisions and outcomes among patients presenting with ACS. Current literature suggests that women are at higher risk of long-term adverse events than their male counterparts after undergoing percutaneous coronary intervention $(\mathrm{PCl})$ for $\mathrm{ACS}$, which is not completely explained by more advanced age and a higher burden of comorbidity [1]. On the other hand, racial differences in patients undergoing PCI for ACS have largely focused on controlling for treatment quality and socioeconomic differences to explain the divergence in outcomes between groups [2]. However, disparities in medical risk factors, pathophysiologic adaptation, and biologic response to injury may also play a role in various sex and racial groups. For example, it is known that a significantly higher percentage of age-adjusted prevalence of hypertension exists in adult non-Hispanic blacks in the United States, compared to other races [3]. Hypertension is a risk factor for left ventricular hypertrophy (LVH), which is a major independent risk factor for cardiovascular mortality [4]. Nevertheless, the association of LVH and mortality has not been borne out in most studies of ACS patients undergoing $\mathrm{PCl}$ [5-8]. However, LVH is a heterogeneous classification and can be subdivided into concentric $(\mathrm{CH})$ and eccentric hypertrophy $(\mathrm{EH})$. Based on new literature, we hypothesized that LVH may be a clinical over-simplification and the true effect of various cardiac geometry on outcomes may be subdued [9]. Indeed, our group has reported that $\mathrm{EH}$ and not $\mathrm{CH}$ is a prognostic variable, independent of sex, in ACS patients undergoing PCI [10]. The long-term consequence of differences in baseline cardiac geometry (as a result of hypertension) in patients undergoing PCI for ACS is ill-defined.

The primary purpose of this study was to clarify whether there were differences among sexual and racial groups in echocardiographic findings reflecting cardiac geometry and adaptation in patients undergoing $\mathrm{PCl}$ for ACS and whether this could explain the difference in outcomes seen between these groups.

\section{Material and methods}

We performed an observational study of patients presenting to an urban, community hospital with ACS who underwent $\mathrm{PCl}$ and were discharged alive between September 23, 2011 and July 31, 2017. The follow-up period of the primary study was 1 year. Qualified patients were identified from an institutional registry that enrolled all patients undergoing $\mathrm{PCl}$ for mandatory reporting to the
New York State Department of Health (NYSDOH) and is exempt from the need for patient consent if de-identification of data for reporting is maintained. We excluded $\mathrm{PCl}$ patients who did not have ACS, based on clinical presentation, elevation in cardiac enzymes (troponin I and/or CK-MB) or ST-segment changes prior to the procedure. Peak troponin I (ng/ml) obtained during the hospital stay was abstracted from medical records. A transthoracic echocardiogram was performed during the index hospitalization utilizing a protocol in line with the American Society of Echocardiography/ Intersocietal Accreditation Commission, and it was interpreted by a board-certified cardiologist. The 2D measurements of left ventricular end diastolic diameter (LVEDd), intraventricular septal diameter (IVS), and posterior wall diameter (PWD) were taken from parasternal long axis views. LV mass index (LVMI) was calculated according to the Devereux equation normalized to body surface area [11]: LVMI $\left(\mathrm{g} / \mathrm{m}^{2}\right)=(0.8 \times(1.04 \times(($ LVEDD + IVSd + $\left.\left.P\left({ }^{3}\right)^{3}-\left(\operatorname{LVDD}^{3}\right)\right)+0.6\right) /$ body surface area.

Relative wall thickness (RWT) was calculated as: $\mathrm{RWT}=(2 \times \mathrm{PWd}) /$ LVEDd.

In accordance with American Society of Echocardiography (ASE) guidelines, an LVMI $\geq 95$ for females and $\geq 115 \mathrm{~g} / \mathrm{m}^{2}$ for males was suggestive of $L V H$, whereas a RWT $\geq 0.42$ was suggestive of concentric adaptations [12]. Four phenotypes of cardiac geometry were identified: normal, concentric remodeling (grouped together as normal geometry), concentric hypertrophy (defined as LVMI $\geq 95$ and RWT $\geq 0.42$ ) and eccentric hypertrophy (defined as LVMI $\geq 95$ and RWT $\geq 0.42$ ). Left ventricular ejection fraction (LVEF) was measured using the 2D, bi-plane or single plane method of disks at the discretion of the interpreting cardiologist. The primary endpoint was all-cause mortality within 1 year after hospital discharge, which was verified by reviewing medical records or by contacting primary care physicians or the patients' families, when necessary. The secondary endpoint was major adverse cardiac events (MACE-B) after discharge, which was defined as a composite of all-cause mortality, non-fatal myocardial infarction, non-fatal stroke, or hospitalization for bleeding, adjudicated based on the primary discharge diagnosis and verified in a similar fashion.

\section{Statistical analysis}

Continuous and categorical variables are presented as the mean with one standard deviation or median with interquartile range, as appropriate, and were compared with Student's $t$-test for means, the Mann-Whitney test for medians, and the two-sided $z$-test or $\chi^{2}$ test for proportions. Event rates were estimated using the Kaplan-Meier time-to-event methodology and compared using 
log-rank tests. Multivariable Cox proportional hazard regression was used to determine the independent predictors of the primary and secondary outcomes. The following demographical covariates were simultaneously included in the model for the primary and secondary outcomes: age, sex, race (white vs. non-white), hypertension, diabetes, prior $\mathrm{MI}$, pre- $\mathrm{PCl}$ creatinine, LVEF $<50 \%$, normal geometry, concentric and eccentric hypertrophy. Two dummy variables were used to include the three groups of cardiac geometries simultaneously with reported hazard ratios $(\mathrm{HR})$ of $\mathrm{CH}$ and $\mathrm{EH}$ in reference to a HR of 1 for normal geometry. The significance level was set at $p<0.05$ (two-sided). All analyses were performed with IBM SPSS Statistics for Mac, version 24 (IBM Corp., Armonk, N.Y., USA). Figures were generated with Microsoft Excel for Mac, version 16.45 (Microsoft Corp., Redmond, WA, USA).

\section{Results}

Between September 2011 and July 2017, 1,610 ACS patients were identified in the institutional registry who underwent $\mathrm{PCl}$. Vital status could not

Table I. Comparative table of baseline demographics by sex and race

\begin{tabular}{|c|c|c|c|c|c|c|}
\hline Parameter & $\begin{array}{c}\text { Male } \\
(n=694)\end{array}$ & $\begin{array}{l}\text { Female } \\
(n=459)\end{array}$ & $P$-value & $\begin{array}{l}\text { White } \\
(n=650)\end{array}$ & $\begin{array}{c}\text { Non-white } \\
(n=503)\end{array}$ & $P$-value \\
\hline Age & $63.3 \pm 17.8$ & $71.1 \pm 17.1$ & $<0.001$ & $66.4 \pm 19.7$ & $66.4 \pm 17.5$ & 0.34 \\
\hline \multicolumn{7}{|l|}{ Race: } \\
\hline White & $423(61)$ & $227(49)$ & $<0.001$ & & & \\
\hline Black & $210(30)$ & $207(45)$ & $<0.001$ & & & \\
\hline Hypertension & $569(82)$ & $416(91)$ & $<0.001$ & $525(81)$ & $460(91)$ & $<0.001$ \\
\hline Dyslipidemia & $510(73)$ & $371(81)$ & 0.005 & $483(74)$ & $398(79)$ & 0.06 \\
\hline Diabetes & $304(44)$ & $250(54)$ & $<0.001$ & $266(41)$ & $288(57)$ & $<0.001$ \\
\hline Smoker & $205(30)$ & $76(4)$ & $<0.001$ & $168(26)$ & $113(22)$ & 0.18 \\
\hline FamHx of CAD & 129 (19) & 79 (17) & 0.36 & $130(20)$ & $78(16)$ & 0.04 \\
\hline Current dialysis & $44(6)$ & $36(8)$ & 0.18 & $27(4)$ & $53(11)$ & $<0.001$ \\
\hline Chronic lung disease & $36(5)$ & $41(9)$ & 0.06 & $52(8)$ & $25(5)$ & 0.04 \\
\hline Prior MI & $158(23)$ & $102(22)$ & 0.20 & $139(21)$ & $121(24)$ & 0.28 \\
\hline Prior HF & $104(15)$ & 88 (19) & 0.052 & $94(14)$ & $98(19)$ & 0.02 \\
\hline Prior CVD & $61(9)$ & $66(14)$ & 0.03 & $63(10)$ & $64(13)$ & 0.10 \\
\hline Prior PAD & $49(7)$ & $45(10)$ & 0.11 & $44(7)$ & $50(10)$ & 0.051 \\
\hline Prior valve Sx & $7(1)$ & $7(2)$ & 0.34 & $9(1)$ & $5(1)$ & 0.54 \\
\hline Prior $\mathrm{PCl}$ & $235(34)$ & $168(37)$ & 0.02 & $222(34)$ & $181(36)$ & 0.51 \\
\hline Prior CABG & $65(9)$ & $33(7)$ & 0.19 & $56(9)$ & $42(8)$ & 0.87 \\
\hline Prior cardiogenic shock & $11(2)$ & $9(2)$ & 0.63 & $15(2)$ & $1(0.1)$ & 0.002 \\
\hline Prior cardiac arrest & $12(2)$ & $11(2)$ & 0.43 & $12(2)$ & $11(2)$ & 0.68 \\
\hline STEMI & $354(51)$ & $199(43)$ & 0.01 & $328(50)$ & $225(45)$ & 0.053 \\
\hline \multicolumn{7}{|l|}{ Echocardiographic data: } \\
\hline IVS [cm] & $1.16 \pm 0.28$ & $1.12 \pm 0.27$ & 0.016 & $1.1 \pm 0.3$ & $1.1 \pm 0.27$ & 0.002 \\
\hline $\mathrm{LVID}_{\mathrm{d}}[\mathrm{cm}]$ & $4.84 \pm 0.73$ & $4.53 \pm 0.74$ & $<0.001$ & $4.6 \pm 0.9$ & $4.7 \pm 0.97$ & $<0.001$ \\
\hline PWD $[\mathrm{cm}]$ & $1.13 \pm 0.24$ & $1.08 \pm 0.21$ & $<0.001$ & $1.1 \pm 0.3$ & $1.1 \pm 0.3$ & 0.005 \\
\hline RWT & $0.48 \pm 0.14$ & $0.49 \pm 0.15$ & 0.25 & $0.45 \pm 0.16$ & $0.48 \pm 0.18$ & $<0.001$ \\
\hline LVMI & $105.2 \pm 37.1$ & $98.8 \pm 33.6$ & 0.003 & $95.6 \pm 37.8$ & $97.8 \pm 45.7$ & $<0.001$ \\
\hline LVEF & $48.1 \pm 16.2$ & $50.4 \pm 16.2$ & 0.02 & $55 \pm 22$ & $53 \pm 22$ & 0.001 \\
\hline \multicolumn{7}{|l|}{ Peak troponin I value: } \\
\hline 15 to 442 & $224(32)$ & $109(23)$ & $<0.001$ & $204(31)$ & $129(26)$ & 0.03 \\
\hline 1 to 15 & $182(26)$ & $152(33)$ & 0.01 & $192(30)$ & $142(28)$ & 0.62 \\
\hline 0.05 to 1 & $195(28)$ & 137 (29) & 0.71 & $161(25)$ & $171(34)$ & $<0.001$ \\
\hline
\end{tabular}

$C A B G$ - coronary artery bypass graft, $C V D$ - cerebral vascular disease, FamHx of CAD - family history of coronary artery disease $H F-$ heart failure, IVS - intraventricular septal diameter, MI - myocardial infarction, LVIDd - left ventricular inner diameter at end diastole, LVEF - left ventricular ejection fraction, $L V M I$ - left ventricular mass index, $P A D-$ peripheral artery disease, $P C I$ - percutaneous coronary intervention, $P W D$ - posterior wall diameter, RWT - relative wall thickness, STEMI - ST-segment elevation myocardial infarction, sx - surgery. 
A

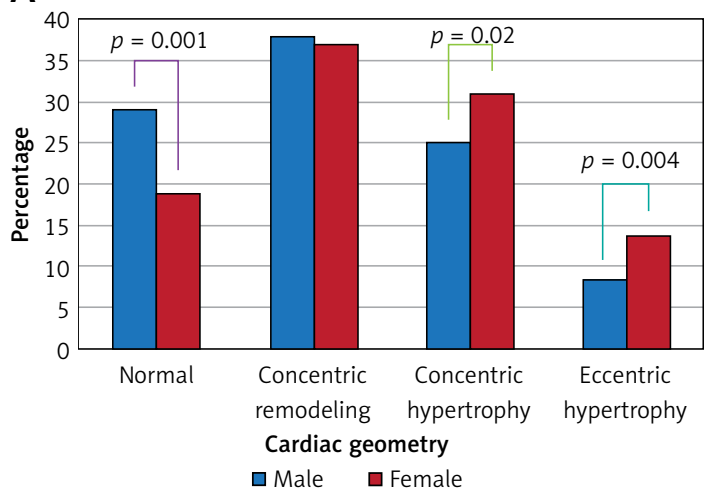

B

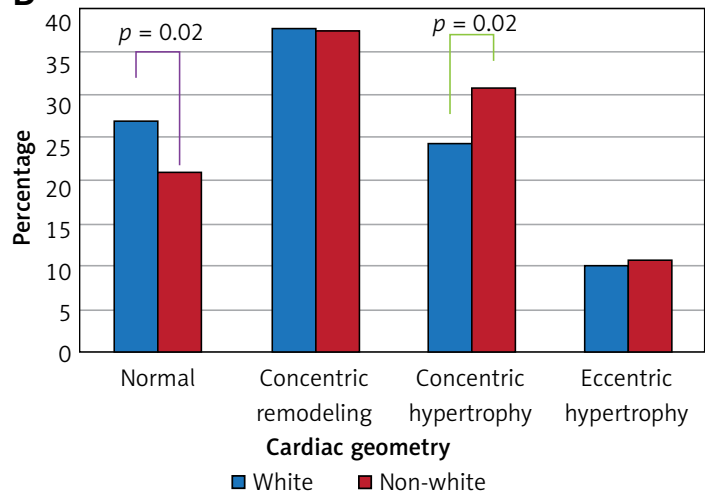

Figure 1. Distribution of cardiac geometry by sex (A) and race (B)

be established in 165 patients. A complete echocardiographic report was not available for 292 patients. A total of 1,153 patients were enrolled in the study. Baseline characteristics, by sex and race, are displayed in Table I. In summary, males tended to be younger, have fewer comorbidities, larger cardiac LV chamber diameter/thickness, more hypertrophic changes, lower LVEF, higher peak troponin values, and were more likely to present with ST-elevation myocardial infarction (STEMI). Whites tended to have fewer comorbidities, smaller cardiac LV chamber diameter/thickness, less hypertrophic changes, higher LVEF, and higher peak troponin values.

Analysis comparing cardiac geometric patterns between males and females revealed a statistically significant difference in the distribution of three phenotypes: normal, concentric hypertrophy, and eccentric hypertrophy: $29 \%$ vs. $19 \%(p=0.001)$, $25 \%$ vs. $31 \%(p=0.02)$, and $8 \%$ vs. $14 \%(p=$ $0.004)$, respectively. The prevalence of concentric remodeling was similar (38\% vs. 37\%, $p=0.64$ ) (Figure $1 \mathrm{~A}$ ). Analysis by race revealed that whites were more likely to present with normal cardiac geometry ( $27 \%$ vs. $21 \%, p=0.02)$ and less likely to present with concentric hypertrophy ( $24 \%$ vs. $31 \%, p=0.02)$ than non-whites. Again, the rates of concentric remodeling were similar among the racial groups (38\% vs. $38 \%$, respectively, $p=0.93$ ) (Figure $1 \mathrm{~B}$ ).

Females were at increased risk of one-year mortality and MACE-B compared to males. There were no differences in outcomes among the different race groups (Table II). Incidence of various MACE-B endpoints are displayed in Table III.

The primary endpoint of all-cause death $(n=$ $89,7.7 \%)$ occurred in $48(10.5 \%)$ females and in $41(6.0 \%)$ males and 48 (7.4\%) whites and 41 (8.2\%) non-whites, $p=0.003$ and 0.65 , respectively (Figures 2 A, B).

In a multivariable analysis, age (hazard ratio (HR (per year) $=1.07$ (1.05-1.09), $p<0.001)$, pre-PCI

Table II. Univariate analysis of 1-year mortality and MACE-B according to sex and race

\begin{tabular}{|lcccc|}
\hline Parameter & Mortality at 1 year & $P$-value & MACE-B at 1 year & $P$-value \\
\hline \begin{tabular}{l} 
Gender: \\
\cline { 2 - 4 } Male $(n=694)$
\end{tabular} & $41(6)$ & 0.01 & 0.002 \\
\hline Female $(n=459)$ & $48(10)$ & & $94(13)$ & \\
\hline Race: & & 0.61 & \\
\hline $\begin{array}{l}\text { White }(n=650) \\
\text { Non-white }(n=503)\end{array}$ & $48(7)$ & & $100(15)$ & \\
\hline
\end{tabular}

MACE-B - major adverse cardiac events; defined as cardiovascular death, non-fatal myocardial infarction, non-fatal stroke, and hospitalization for bleeding.

Table III. Incidence of various major adverse cardiac events and bleeding endpoints by sex

\begin{tabular}{|lccc|}
\hline Parameter & Male $(n=694)$ & Female $(n=459)$ & $P$-value \\
\hline All-cause death & $42(6)$ & $48(10)$ & 0.01 \\
\hline Non-fatal MI & $31(4)$ & $34(7)$ & 0.02 \\
\hline Non-fatal stroke & $2(0.2)$ & $6(1)$ & 0.06 \\
\hline Hospitalization for bleeding & $28(4)$ & $21(5)$ & 0.41 \\
\hline
\end{tabular}

MI- myocardial infarction. 

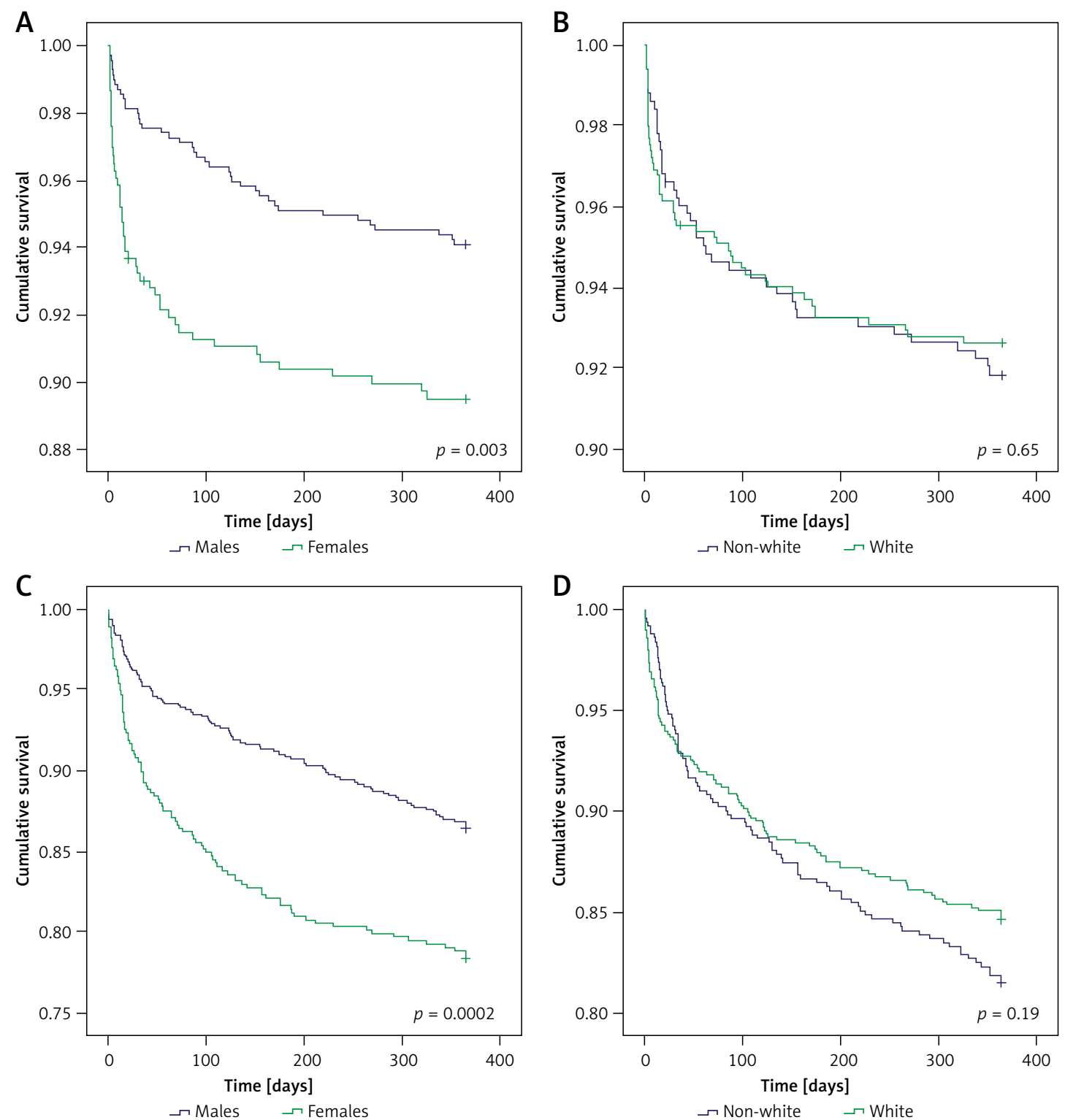

Figure 2. A - All-cause mortality by sex. B - All-cause mortality by race. C - Major adverse cardiac events by sex.

D - Major adverse cardiac events by race

creatinine (HR (per $1 \mathrm{mg} / \mathrm{dl})=1.11(1.01-1.22)$, $p=0.023)$, and LVEF $<50 \%(H R=2.69(1.68-4.30)$, $p<0.001)$ were significant predictors of survival, whereas race, sex, hypertension, diabetes, prior $\mathrm{MI}$, and cardiac geometry were not (Table IV).

Males with EH had similar MACE-B outcomes as females with $\mathrm{EH} 1$ year after $\mathrm{PCl}(29 \%$ vs. $32 \%$, respectively, $p=0.77$ ) (Table $\mathrm{V}$ ).

Age (HR (per year $=1.04(1.02-1.05), p<0.001)$, female sex $(H R=1.38(1.01-1.87), p=0.04)$, diabetes $(H R=1.43(1.05-1.95), p=0.02)$, pre-PCl creatinine $(\mathrm{HR}$ per $1 \mathrm{mg} / \mathrm{dl})=1.10(1.03-1.17)$, $p=0.003)$, LVEF $<50 \%(H R=1.74(1.28-2.36)$, $p<0.001)$, and eccentric hypertrophy $(H R=1.54$ (1.02-2.33), $p=0.04$ ) were significant predictors of MACE-B, whereas race, hypertension, prior $\mathrm{MI}$, and concentric cardiac geometry were not (Table IV).

\section{Discussion}

The major findings from this single-institution, observational study, in which 2D echocardiographic data from 1,153 patients with an index ACS treated with $\mathrm{PCl}$ were compared by sex and race are as follows: 1) sexual differences in the distribution of $\mathrm{EH}$ place females in a higher risk category, whereas racial differences differ only in $\mathrm{CH} ; 2$ ) females and males exhibit similar outcome rates once $\mathrm{EH}$ develops; 3 ) $\mathrm{CH}$ is a benign adaptation in one-year outcomes in ACS patients undergoing $\mathrm{PCl}$ and as such racial outcomes did not differ between groups; 4) differences in cardiac geometry did not account for the difference in outcomes seen between sexes.

The premise that sex affects outcome in patients undergoing $\mathrm{PCl}$ for symptomatic $\mathrm{CAD}$ has 
The effect of cardiac geometry variation according to sex and race on outcomes in patients with acute coronary syndrome undergoing percutaneous coronary intervention

Table IV. Independent predictors of 1-year all-cause mortality and major adverse clinical events

\begin{tabular}{|c|c|c|}
\hline Variable & HR $(95 \% \mathrm{Cl})$ & $P$-value \\
\hline \multicolumn{3}{|l|}{ All-cause mortality: } \\
\hline Age & $1.07(1.05-1.09)$ & $<0.001$ \\
\hline Sex & $1.45(0.92-2.28)$ & 0.11 \\
\hline Race & $1.03(0.66-1.61)$ & 0.90 \\
\hline Hypertension & $3.53(0.84-14.9)$ & 0.09 \\
\hline Diabetes & $1.43(0.91-2.24)$ & 0.12 \\
\hline Prior MI & $0.94(0.58-1.52)$ & 0.79 \\
\hline Pre-PCl creatinine & $1.11(1.01-1.22)$ & 0.023 \\
\hline LVEF $<50 \%$ & $2.69(1.68-4.30)$ & $<0.001$ \\
\hline Normal geometry (reference): & 1 & \\
\hline Concentric hypertrophy & $0.89(0.54-1.50)$ & 0.67 \\
\hline Eccentric hypertrophy & $1.11(0.61-2.05)$ & 0.73 \\
\hline \multicolumn{3}{|l|}{ Major adverse cardiac events: } \\
\hline Age & $1.04(1.02-1.05)$ & $<0.001$ \\
\hline Sex & $1.38(1.01-1.87)$ & 0.04 \\
\hline Race & $0.97(0.71-1.31)$ & 0.83 \\
\hline Hypertension & $1.005(0.58-1.75)$ & 0.99 \\
\hline Diabetes & $1.43(1.05-1.95)$ & 0.02 \\
\hline Prior MI & $1.06(0.76-1.47)$ & 0.74 \\
\hline Pre-PCl creatinine & $1.10(1.03-1.17)$ & 0.003 \\
\hline LVEF $<50 \%$ & $1.74(1.28-2.36)$ & $<0.001$ \\
\hline Normal geometry (reference): & 1 & \\
\hline Concentric hypertrophy & $1.01(0.71-1.43)$ & 0.96 \\
\hline Eccentric hypertrophy & $1.54(1.02-2.33)$ & 0.04 \\
\hline
\end{tabular}

$L V E F$ - left ventricular ejection fraction, $L V H$ - left ventricular hypertrophy; defined as $L V M I \geq 115$ in males, and $\geq 95$ in females, MACE major adverse cardiac events; defined as cardiovascular death, non-fatal myocardial infarction, non-fatal stroke, and hospitalization for bleeding, MI-myocardial infarction.

Table V. Univariate comparison of 1-year mortality and MACE-B in EH group between sexes

\begin{tabular}{|c|c|c|c|c|}
\hline Parameter & Mortality at 1 year & $P$-value & MACE-B at 1 year & $P$-value \\
\hline Sex: & & 0.41 & & 0.77 \\
\hline Males with $\mathrm{EH}(n=58)$ & $7(12)$ & & $17(29)$ & \\
\hline Females with $\mathrm{EH}(n=63)$ & $11(17)$ & & $20(32)$ & \\
\hline
\end{tabular}

EH - eccentric hypertrophy, MACE-B - major adverse cardiac events; defined as cardiovascular death, non-fatal myocardial infarction, non-fatal stroke, and hospitalization for bleeding.

been extensively studied and debated, with mixed results [7-20]. However, the conflicting findings can largely be attributed to differences in study design and group selection. The studies that found no difference in long-term mortality between men and women enrolled a sizeable proportion of patients treated for stable angina or atypical chest pain [20-26]. In contrast, an increase in long-term mortality or MACE-B risk was found in those studies that included only patients treated for ACS [13-19]. Yet, a fair degree of heterogeneity exists even in those studies focusing on ACS patients. For example, sub-group analyses by Raphael et al. revealed that the higher mortality seen in women is due to death from non-cardiac causes, ex- plained by higher baseline age and comorbidities [13]. More recently, Kosmidou et al. reported only a statistically significant increased risk of MACE-B at 5 years in females, while the increased risk for all-cause mortality disappeared upon adjustment for baseline and procedural characteristics [17]. We report findings in agreement of females being at increased risk of adverse outcomes following hospital discharge after PCI for ACS.

Our findings are novel because we recently integrated a new clinical variable - cardiac geometry - that may be useful in risk stratifying patients with respect to death or MACE-B [10]. We now investigate the interaction between it and race and sex to assess whether differing cardiac geometry 
may be more prevalent among certain race or sex groups. As hypertension is more common in females and in non-Hispanic blacks, they are more likely to exhibit hypertrophic cardiac geometries, both concentric and eccentric [27]. Although racial differences in 1-year mortality or MACE-B were not observed, such divergence in time-toevent curves may occur beyond 1 year given the increased prevalence of hypertrophic changes in non-white populations in our cohort and the fact that LVH is an independent predictor of mortality [28]. In our study, CH was not independently associated with worse outcomes in 1 year; thus the lack of racial differences in outcomes is not surprising. It was found that females tend to have higher frequencies of EH than males, which highlights novel sex differences in cardiac geometry portending higher risk. In agreement with prior studies, sex differences in MACE-B were observed in our analysis even after controlling for age and baseline co-morbidities. However, our analysis did not reveal $\mathrm{EH}$ to interact with sex in observed MACE-B events 1 year after $\mathrm{PCl}$, indicating cardiac geometry independent mechanisms in sex and MACE-B.

It is currently not known whether disparities in medical risk factors, pathophysiologic adaptation, and/or biologic response to injury are responsible for the sexual differences in worse outcomes seen in ACS patients undergoing PCl. Our analysis and others have demonstrated that sex is predictive of worse outcomes independent of medical risk factors. Based on the results of this study, it seems unlikely that sex differences in biologic response to LVH and acute $\mathrm{MI}$ in those with $\mathrm{EH}$ contribute to worse outcomes. Moreover, the results from this study do not support the notion that the increased prevalence of $\mathrm{EH}$ in females presenting with ACS may account for the differences in outcomes reported in the literature, since the difference in MACE-B between sexes persisted in subgroup analysis without EH (unpublished data). An important question for future studies may be to explain why females presenting with ACS have a higher prevalence of $\mathrm{EH}$ and whether this may be a predictive variable.

We recognize important limitations to our study design, observations and conclusions. The first is the relatively small cohort of patients included in this single-center study when compared to multi-centered randomized clinical trials, which may not be generalizable to the US population as a whole. Second, data were collected retrospectively from the electronic medical records, and were not recorded in a standardized and systematic manner, thus obscuring confounders that cannot be optimally controlled for. A strength of our study is the relatively high percentage of females and minority groups enrolled in our institutional registry.

In conclusion, despite these limitations, we conclude that in patients with recent acute coronary syndrome revascularized with percutaneous coronary intervention, 2D echocardiography identifies females at higher risk for worse outcomes partly because they are more likely to express the eccentric hypertrophy phenotype, which is an independent predictor of worse outcomes. However, our analysis did not reveal $\mathrm{EH}$ to interact with sex in observed adverse events 1 year after $\mathrm{PCl}$, indicating mechanisms independent of cardiac geometry in sex and adverse outcomes. Further studies are needed to explore the variables responsible for the increased prevalence of $\mathrm{EH}$ in female ACS patients.

\section{Conflict of interest}

The authors declare no conflict of interest.

\section{References}

1. O'Donoghue ML, Sarma AA. Understanding the sex paradox after percutaneous coronary intervention: leveling the playing field. J Am Coll Cardiol 2020; 75: 1641-3.

2. Cavender MA, Rassi AN, Fonarow GC, et al. Relationship of race/ethnicity with door-to-balloon time and mortality in patients undergoing primary percutaneous coronary intervention for ST-elevation myocardial infarction: findings from get with the guidelines-coronary artery disease. Clin Cardiol 2013; 36: 749-56.

3. Fryar CD, Ostchega Y, Hales CM, Zhang G, Kruszon-Moran D. Hypertension prevalence and control among adults: United States, 2015-2016. NCHS Data Brief 2017; 289: 1-8.

4. Havranek EP, Froshaug DB, Emserman CDB, et al. Left Ventricular hypertrophy and cardiovascular mortality by race and ethnicity. Am J Med 2008; 121: 870-5.

5. Haider AW, Larson MG, Benjamin EJ, Levy D. Increased left ventricular mass and hypertrophy are associated with increased risk for sudden death. J Am Coll Cardiol 1998; 32: 1454-9.

6. Stiermaier T, Pöss J, Eitel C, et al. Impact of left ventricular hypertrophy on myocardial injury in patients with ST-segment elevation myocardial infarction. Clin Res Cardiol 2018; 107: 1013-20.

7. Brown DL. Effect of left ventricular hypertrophy on longterm survival of patients with coronary artery disease following percutaneous coronary intervention. Heart Int 2009; 4: e9.

8. Kim YH, Her AY, Choi BG, et al. Impact of left ventricular hypertrophy on longterm clinical outcomes in hypertensive patients who underwent successful percutaneous coronary intervention with drug-eluting stents. Medecine 2018; 97: e12067.

9. Nauta JF, Hummel YM, Tromp J, et al. Concentric vs. eccentric remodelling in heart failure with reduced ejection fraction: clinical characteristics, pathophysiology and response to treatment. Eur J Heart Fail 2020; 22: 1147-55.

10. Ha ET, Cohen M, Peterson SJ, Aronow WS. Eccentric hypertrophy predicts adverse events in patients undergo- 
ing percutaneous coronary intervention for acute coronary syndrome. Arch Med Sci Atheroscler Dis 2021; 6: e21-7.

11. Devereux RB, Alonso DR, Lutas EM, et al. Echocardiographic assessment of left ventricular hypertrophy: comparison to necropsy findings. Am J Cardiol 1986; 57 : 450-8.

12. Lang RM, Badano LP, Victor MA, et al. Recommendations for cardiac chamber quantification by echocardiography in adults: an update from the American Society of Echocardiography and the European Association of Cardiovascular Imaging. J Am Soc Echocardiogr 2015; 28: 1-39.e14

13. Raphael CE, Singh $M$, Bell $M$, et al. Sex differences in long-term cause-specific mortality after percutaneous coronary intervention temporal trends and mechanisms. Circ Cardiovasc Interv 2018; 11: e006062.

14. Kunadian V, Qiu W, Lagerqvist B, et al. Gender differences in outcomes and predictors of all-cause mortality after percutaneous coronary intervention (Data from United Kingdom and Sweden). Am J Cardiol 2017; 119: 210-6.

15. Pendyala LK, Torguson R, Loh JP, et al. Comparison of adverse outcomes after contemporary percutaneous coronary intervention in women versus men with acute coronary syndrome. Am J Cardiol 2013; 111: 1092-8.

16. Glaser R, Selzer F, Jacobs AK, et al. Effect of gender on prognosis following percutaneous coronary intervention for stable angina pectoris and acute coronary syndromes. Am J Cardiol 2006; 98: 1446-50.

17. Kosmidou I, Leon MB, Zhang Y, et al. Long-term outcomes in women and men following percutaneous coronary intervention. J Am Coll Cardiol 2020; 75: 1631-40.

18. Epps KC, Holper EM, Selzer F, et al. Sex differences in outcomes following percutaneous coronary intervention according to age. Circ Cardiovasc Qual Outcomes 2016; 9 (2 Suppl 1): S16-25.

19. Heer T, Hochadel M, Schmidt K, et al. Sex differences in percutaneous coronary intervention-insights from the coronary angiography and $\mathrm{PCl}$ registry of the German Society of Cardiology. J Am Heart Assoc 2017; 6: e004972.

20. Fokkema ML, James SK, Albertsson P, et al. Population trends in percutaneous coronary intervention: 20-year results: from the SCAAR (Swedish Coronary Angiography and Angioplasty Registry). J Am Coll Cardiol 2013; 61: 1222-30.

21. Kelsey SF, James M, Holubkov AL, et al. Results of percutaneous transluminal coronary angioplasty in women: 1985-1986 National Heart, Lung, and Blood Institute's Coronary Angioplasty Registry. Circulation 1993; 87: 720-7.

22. Jacobs AK, Johnston JM, Haviland A, et al. Improved outcomes for women undergoing contemporary percutaneous coronary intervention: a report from the national heart, lung, and blood institute dynamic registry. J Am Coll Cardiol 2002; 39: 1608-14.

23. Gudnadottir GS, Andersen K, Thrainsdottir IS, James SK, Lagerqvist B, Gudnason T. Gender differences in coronary angiography, subsequent interventions, and outcomes among patients with acute coronary syndromes. Am Heart J 2017; 191: 65-74.

24. Sarma AA, Braunwald E, Cannon CP, et al. Outcomes of women compared with men after non-ST-segment elevation acute coronary syndromes. J Am Coll Cardiol 2019; 74: 3013-22.
25. Anderson ML, Peterson ED, Matthew Brennan J, et al. Short-and long-term outcomes of coronary stenting in women versus men: results from the national cardiovascular data registry centers for medicare \& medicaid services cohort. Circulation 2012; 126: 2190-9.

26. Batchelor W, Kandzari DE, Davis S, et al. Outcomes in women and minorities compared with white men 1 year after everolimus-eluting stent implantation: insights and results from the PLATINUM diversity and PROMUS element plus post-approval study pooled analysis. JAMA Cardiol 2017; 2: 1303-13.

27. Muntner P, Carey RM, Gidding S, et al. Potential U.S. population impact of the 2017 ACC/AHA high blood pressure guideline. J Am Coll Cardiol 2018; 137: 109-18.

28. Verdecchia P, Carini G, Circo A, et al. Left ventricular mass and cardiovascular morbidity in essential hypertension: the MAVI study. J Am Coll Cardiol 2001; 38: 1829-35. 